\section{Premierenreich ins neue Jahr}

_ Bislang mussten Sie sich auf den Kopf stellen, wenn Sie den praxisprofi lesen wollten. Das haben wir geändert. „Die Chefseiten“ erstrahlen ab Seite 34 in neuem Glanz. Blättern Sie doch mal rein!

_ Auf den Kopf gestellt haben wir auch das Programm des ergotags. Sieben Jahre lang richtete er sich an Pädiatrie-Fans, jetzt dürfen sich die Anhänger der Erwachsenen-Neurologie freuen. Am 26. Januar 2014 heißt es in Stuttgart „Teilhaben - (neuro)logisch!“. Eine Premiere.

_ Eine Premiere ist das auch für mich. Denn ich habe nicht nur die Programmplanung für die Veranstaltung übernommen, sondern freue mich auch schon darauf, sie zu moderieren. Ein Kribbeln macht sich bereits bei mir breit, denn auf einer Bühne stand ich zum letzten Mal mit acht Jahren bei einer Ballettaufführung. Aber bekanntlich wächst man ja mit seinen Aufgaben. 2014 wird spannend, ich habe das so im Gefühl.

_ Im Namen des gesamten ergopraxis-Teams wünsche ich Ihnen ein erfolgreiches und gesundes neues Jahr! Wir freuen uns auch 2014 über Ihre inspirierenden Artikelideen und anregenden Rückmeldungen!

\begin{tabular}{|l|l|}
\hline \multicolumn{1}{|c|}{ ZU GEWINNEN } \\
Kursplatz \\
$\mathbf{1}$ Kurs „Bewegungsanalyse/ \\
Normale Bewegung“ & Seite 53 \\
Bücher & \\
3-mal „Aku-Taping“ $\quad$ Seite 22 \\
3-mal „Einführung in die \\
Beratungspsychologie“ Seite 31 \\
Und außerdem.... \\
3 Bean Bag Jonglierbälle Seite 44 \\
\hline
\end{tabular}

Das ergopraxis-Team von links: Elke Oldenburg (Redaktionsleitung), Simone Gritsch (Redaktion), Annette Alkemade (Redaktionsassistenz), Annette Hampp (Marketing), Maria Czyganowski (Redaktion), Julia Belitz (Herstellung) 